\title{
A Prática Social de Gerentes Universitários em uma Instituição Pública
}

\author{
Adriana Ventola Marra \\ Marlene Catarina de Oliveira Lopes Melo
}

\begin{abstract}
Resumo
A ação e o trabalho gerenciais são práticas sociais; ou seja, devem ser compreendidos a partir da inter-relação dos planos organizacional e comportamental com o contexto da sociedade em que a organização e seus gerentes estão insertos. Com base nesse pressuposto e com o objetivo de caracterizar e analisar as práticas gerenciais de professores com cargos de chefia intermediária em sua ação cotidiana, foi realizado um estudo de caso em uma Universidade Federal. A pesquisa foi desenvolvida utilizando-se estratégia qualitativa. Os dados revelam que as atividades gerenciais na universidade estão diluídas e incorporadas em práticas sociais, realizadas sem planejamento, imperando o imediatismo e o improviso. Algumas peculiaridades da gestão universitária, tais como cargo colegiado, burocracia, fatores políticos, jogo de poder, falta de formação administrativa, administração dos pares, caráter transitório do cargo e a própria cultura da universidade pública, aumentam o caráter contraditório e os conflitos inerentes à função gerencial.
\end{abstract}

Palavras-chave: universidade; gerente intermediário; prática social; cultura.

\begin{abstract}
The action and the managerial work are social practices; they should be seen as an interrelation between organizational and behavioral in the society context, and the context of society in which that organization and its managers are inserted. On the basis and with the objective of characterize and analyze the managerial practices of professors with intermediate leadership in their routine action, was carried out a study in the Universidade Federal. The research was developed utilizing qualitative strategy. The facts reveal that the managerial activities in the university are diluted and incorporated in social practices, carried out without planning, commanding the immediate and improvise. Some peculiarities from management university, like charge collegiate, bureaucracy, political factors, power struggle, absence of administrative skills, administration of the pairs, the transitory character of the position and the public university culture, they increase the contradictory character and the inherent conflict to managerial function.
\end{abstract}

Key words: university; middle manager; social practice; culture. 


\section{INTRODUÇÃO}

Cobra-se, atualmente, mais eficiência e qualidade das Instituições de Ensino Superior (IES). Além de ofertarem ensino de qualidade, elas devem desenvolver pesquisa básica, aplicada e tecnológica, em busca de conhecimentos científicos que dêem respostas aos desafios e problemas sociais, econômicos, políticos e culturais, de forma concreta e regionalizada. Em particular, as universidades federais têm sido alvo de questionamentos por parte da sociedade e do governo acerca de seus reais objetivos, da rigidez da sua estrutura burocrática, da ineficiência no uso dos recursos e da pouca pertinência social dos serviços prestados.

Nesse cenário, os gerentes das instituições públicas universitárias - em sua grande maioria, professores - são os responsáveis pela administração da universidade, adotando práticas gerenciais, decisões e ações que viabilizam o alcance dos objetivos organizacionais. O professor-gerente acaba por acumular as atividades gerenciais com as acadêmicas.

As práticas gerenciais, particularmente nas universidades federais, apresentam características peculiares, que merecem ser estudadas. Deste modo, coloca-se como questão central deste artigo: Como se caracterizam, cotidianamente, as práticas gerenciais de professores de uma Universidade Federal em cargos de chefia intermediária?

Com o objetivo de caracterizar e analisar as práticas gerenciais de professores universitários em instituição pública com cargos de chefia intermediária e tendo como pressuposto teórico a gestão como prática social (REED, 1997), foi realizado um estudo de caso qualitativo em uma Universidade Federal situada no interior de Minas Gerais.

\section{O Gerente e as Práticas Gerenciais}

Fayol (1970) foi um dos primeiros a identificar a necessidade de se constituir um corpo de saber administrativo, para que fosse aperfeiçoado e transmitido a todos os que tivessem de gerir ou administrar uma organização. 
Seguiram-se a Fayol (1970) outros estudos clássicos sobre o gerente e a função gerencial. Dentre eles destacamos Barnard (1971) e Likert (1979) com o foco voltado para as pessoas e suas relações; e Mintzberg (1973) que afirmou que os gerentes estão orientados para a ação, e não para reflexão; que os executivos preferem a mídia verbal, principalmente, telefonemas e reuniões; e que programas de executivos para organizar tempo, processar informações e tomar decisões permanecem mais trancados em sua cabeça do que realmente são postos em prática.

A análise dos trabalhos relacionados à questão do gerente evidencia que permanece certa dificuldade em estabelecer com exatidão os limites, as atribuições, as prioridades e as expectativas para o nível gerencial. Motta (1991) ressalta essa dificuldade ao afirmar que:

“Atualmente já se aceita tratar a função gerencial como extremamente ambígua e repleta de dualidades, cujo exercício se faz de forma fragmentada e intermitente. Com isso torna-se difícil defini-la de forma análoga a outras profissões” (p. 20).

Mostra-se, portanto, relevante o aprofundamento de estudos que analisem a questão gerencial de forma mais ampla e que, de certa forma, contribuam para o esclarecimento das práticas gerenciais nos dias atuais.

Reed (1997) identifica três perspectivas mais usualmente encontradas nos estudos sobre gestão: a técnica; a política; e a crítica. Na abordagem técnica a gestão é vista como instrumento tecnológico neutro e racional, que objetiva alcançar resultados coletivos, preestabelecidos pela organização e que são inatingíveis sem sua aplicação. A gestão é concebida a partir de estruturas racionais formalizadas e de sistemas de controle capazes de garantir a eficiência, sob a coordenação de ações humanas. A abordagem política concebe a gestão como processo social, voltado para a regulação do conflito entre grupos de interesse, num ambiente cheio de incertezas sobre os critérios de avaliação do desempenho organizacional. As estruturas organizacionais são vistas como resultado de processos dinâmicos e contínuos de negociações entre interesses, advindos de interpretações distintas de seus atores, no que tange às regras e objetivos organizacionais. A perspectiva crítica considera a gestão como um mecanismo de controle que funciona para satisfazer o sistema econômico capitalista e para disseminar sua ideologia. Os conflitos políticos, entre os gestores ou entre grupos, são entendidos como subordinados à estrutura de relações de produção capitalista em que estão incorporados e à satisfação dos imperativos econômicos do sistema.

Para Reed (1997), nas perspectivas técnica, política e crítica, o gerente tornase apenas um agente de imperativos funcionais, figurando fora das práticas 
sociais ${ }^{(1)}$ em que ele está envolvido no seu cotidiano. Desse modo, o autor analisa a gestão como prática social. Segundo essa perspectiva devem ser incorporados, ao mesmo tempo, à análise da gestão os níveis institucional, organizacional e comportamental, permitindo as interseções entre a ação gerencial, a dinâmica da organização e o contexto macroestrutural. Para o autor, nas perspectivas anteriores, os gerentes não são mais que simples agentes de ordens imperativas geradas externamente às práticas sociais que fazem parte do seu cotidiano. Conseqüentemente, nenhuma delas é capaz, isoladamente, de tratar satisfatoriamente as ambigüidades e complexidades das práticas gerenciais.

Na perspectiva praxeológica, a gestão é vista como atividade que visa à contínua articulação de práticas complexas e diversificadas, que estão, às vezes, desarticuladas e fragmentadas (REED, 1997).

Reed (1997) analisa os gerentes como profissionais cujo exercício profissional exige a utilização de saberes que os auxiliem a lidar com as exigências contraditórias e com as pressões organizacionais. Em outras palavras, os gerentes são agentes organizacionais que não devem ser vistos só como responsáveis pelo exercício da disciplina e dos interesses organizacionais, mas também como vivenciadores de conflitos e contradições, dado que as organizações são, por excelência, lócus de contradições estruturais e processuais que se refletem na prática gerencial. Para tanto, eles necessitam de mecanismos especializados e desenvolvem processos para regularem os conflitos decorrentes das relações de poder presentes no ambiente organizacional. A análise da regulação de conflitos nas relações de trabalho parte de dois pressupostos básicos: o poder é uma característica fundamental de todas as relações sociais; e toda estrutura social organizada é portadora de conflitos e de processos de regulação desses conflitos (MELO, 1991).

\section{Contexto Macroestrutural: Cultura e Gerência no Brasil}

Para melhor entendimento das organizações brasileiras deve-se buscar traços gerais da nossa cultura, porquanto, sendo a gestão uma prática social, seu exercício está sujeito aos valores, princípios e tradições de uma determinada sociedade (FREITAS, 1997). As organizações não existem no vazio, e sim dentro do que Barbosa (1996) chama de contexto significacional. Portanto, para gerenciar tais organizações, por mais que se busque a objetividade, é necessário considerar as influências dos valores, princípios e tradições da sociedade, muitos deles implicando uma análise, se realmente se deseja atingir os objetivos organizacionais. 
Da Matta $(1990,1997)$ destaca as relações pessoais como elemento estrutural marcante na sociedade brasileira. Para ele, no Brasil existe um convívio conflituoso entre o domínio do indivíduo, caracterizado pelo mundo da rua, e o da pessoa, caracterizado pelo mundo da casa. O mundo da rua é aquele dos aspectos impessoais-legais (todos são iguais perante a lei), das regras e normas, da gratuidade de serviços públicos. O mundo da casa é aquele das relações familiares, da proteção, da intimidade e da hierarquia. Os domínios do indivíduo e o da pessoa convivem lado a lado nas relações sociais no Brasil, criando situações de um sistema legal que pode ser constantemente burlado em função de uma moralidade pessoal.

Para Barros e Prates (1996), o sistema de ação cultural brasileiro é composto de quatro subsistemas: institucional, pessoal, dos líderes e dos liderados. O subsistema institucional está relacionado aos traços culturais presentes no espaço da rua, definido por Da Matta (1997), ao passo que os traços típicos do espaço da casa compõem o subsistema pessoal. O subsistema dos líderes aglutina traços encontrados naqueles que detêm o poder, enquanto o subsistema de liderados abrange os aspectos culturais mais próximos daqueles subordinados ao poder.

Esses subsistemas apresentam interseções entre si, podendo ser verificados traços culturais comuns. Especificadamente, o subsistema dos líderes, próprio das posições gerenciais, apresenta os seguintes traços situacionais: concentração de poder, personalismo e paternalismo (BARROS; PRATES, 1996). A concentração de poder combina as estruturas de poder com suas principais bases de autoridade. A autoridade legítima baseia-se na tradição, na racionalidade legal e no carisma (WEBER, 1982). As formas de estrutura de poder podem ser descritas como autocracia (concentração de poder em um só indivíduo), poliarquia limitada (existência de um grupo monopolista de poder) e poliarquia plena (existência de ampla participação nas decisões) (BARROS; PRATES, 1996). A sociedade brasileira tem-se apoiado na força militar tradicionalista e no poder racional legal para o estabelecimento e manutenção da autoridade, criando uma cultura de concentração do poder baseada na hierarquia/subordinação.

Segundo Barros e Prates (1996), a combinação da concentração de poder e do personalismo tem como síntese o paternalismo, que se apresenta como o patriarcalismo e o patrimonialismo. Tradicionalmente, a sociedade brasileira é patriarcal. Nela, o patriarca tudo pode, cabendo aos outros membros do clã pedir e obedecer. Caso contrário, podem ser excluídos do âmbito das relações. Os gestores assumem posturas paternalistas; ou seja, concentram poder e se valem do carisma e da imagem pessoal em suas relações com os subordinados. 
Elementos desse contexto macroestrutural encontram-se inseridos em graus variados nas universidades públicas brasileiras, implicando a adoção de práticas gerenciais que sejam capazes de lidar com esses pressupostos, sob pena de incorrerem em perdas econômicas e em desmotivação e descomprometimento das pessoas com a instituição da qual fazem parte.

\section{A Dinâmica da Universidade Pública: Perspectiva Cultural}

De acordo com Martin (1992) as formas de se estudar cultura ${ }^{(2)}$ podem ser separadas em perspectivas de integração, diferenciação e fragmentação. Dentro do enfoque de integração é estudada a cultura organizacional, partindo-se do pressuposto de que a cultura pode ser criada e perpetuada pelos gestores e constitui-se em uma variável que pode fazer com que os membros da organização tenham os mesmos valores e se mantenham unidos. Na perspectiva da diferenciação, são enfatizadas as diferenças entre os diversos grupos que fazem parte da organização, cada um com sua cultura própria. Segundo a perspectiva da fragmentação, existem valores que são partilhados temporariamente pelos membros da organização, e a cultura passa a ser vista como um processo historicamente construído (CAVEDON; FACHIN, 2000).

Cavedon e Fachin (2000) sugerem que sejam realizadas pesquisas sobre a questão cultural das organizações, empregando-se as três perspectivas propostas por Martin (1992). Rodrigues (1991) acrescenta que existem culturas grupais numa organização, mas a estas se intercala uma cultura organizacional, que reflete e abrange as relações entre aquelas. Para efeitos desta pesquisa, adotou-se uma abordagem que reconhece a existência de uma cultura organizacional com propriedades comuns e valores dominantes coexistindo com uma diversidade cultural nas organizações (RODRIGUES, 1991).

Assim como outros tipos de organização, a universidade é rica em cultura, subculturas, ritos, grupos de referência, e nichos de poder. O sistema de crenças ou ideologias nas instituições acadêmicas está representado por três níveis segundo Dill ${ }^{(3)}$ (apud HERGURNER; REEVES, 2000): cultura organizacional, que depende da universidade; cultura da profissão acadêmica, de uma forma geral; e culturas das disciplinas ou dos grupos de disciplinas. Todos os níveis são influenciados pela cultura do local, onde está inserta a universidade. Cabe acrescentar ao modelo de Dill (1992), na perspectiva da fragmentação, as culturas dos grupos ou subculturas na universidade, aqui considerada como detentora de três grandes grupos distintos: docentes, discentes e funcionários. 
Procurando entender essa heterogeneidade cultural da universidade pública, Cavedon e Fachin (2000) apontam as representações culturais dos grupos dos professores, dos alunos e dos funcionários da instituição. Em relação à percepção que os docentes têm acerca da universidade, os autores destacam que em sua fala são privilegiados os aspectos de: deterioração da universidade por falta de recursos materiais; importância do nome da universidade em face da sociedade; inexistência de controle sobre a atividade docente; cobrança por publicações; burocracia da universidade; utilização do nome da universidade como vitrine; confronto entre professores novos e antigos; apego à universidade (a maioria dos professores foi aluno da própria universidade); e a excelência em pesquisa. Esses aspectos indicam a visão que o grupo de docentes tem da universidade pública. E é com essa visão que eles vão ocupar as funções gerenciais na universidade.

Outro aspecto marcante na cultura da universidade pública é seu peculiar processo de tomada de decisão. Dagnino e Gomes (2001) ressaltam que o processo decisório na universidade pública é presidido por um reitor, assessorado pelos seus pró-reitores, cada um encarregado das várias áreas-meio e áreas-fim em que se dá a atuação da universidade, por inúmeras comissões, órgãos colegiados etc. Essa cadeia de comando é encimada por um Conselho Superior, que tem a responsabilidade de tomar as decisões concernentes à instituição e de elaborar seu planejamento estratégico, dentre outras, mas que se resume em acolher as recomendações das comissões, referendar os atos executivos da Reitoria e acatar as decisões tomadas nas instâncias acadêmicas. Os autores complementam que a universidade pública tem um processo de decisão que se dá mediante o mútuo ajuste entre atores pouco diferenciados, pois o reitor, os diretores de unidade e os chefes de departamento são professores e, portanto, pares que amanhã perderão seus mandatos.

Em suma, a cultura da universidade pública pode ser caracterizada por forte resistência a mudanças; pelo predomínio dos professores na gestão universitária; pela existência de subculturas de acordo com o departamento, o curso, a área de conhecimento e os grupos da comunidade universitária; pela valorização da qualidade, excelência e liberdade acadêmica; pelo respeito às decisões colegiadas; e por forte prevalência dos aspectos políticos no modelo de gestão. Esses valores estão presentes na maioria das universidades federais brasileiras, e as práticas gerenciais de seus chefes de departamento e coordenadores de curso/programa influenciam e são influenciadas por eles. 


\section{Aspectos Metodológicos}

Esta pesquisa caracterizou-se como estudo qualitativo, do tipo descritivo, em que se optou pelo método do estudo de caso. O universo foi composto pelos professores que ocupavam cargo de chefes de departamento e coordenadores de curso de graduação e de pós-graduação da Universidade Federal pesquisada, com pelo menos dezoito meses de exercício na função gerencial, permitindo a análise da prática social daqueles que já possuíam certa vivência gerencial.

Segundo a Diretoria de Recursos Humanos da universidade pesquisada, existiam 28 (vinte e oito) chefes de departamento e 56 (cinqüenta e seis) coordenadores de curso de graduação e de programas de pós-graduação em agosto de 2002. Desse total de 84 gerentes intermediários, apenas 40 possuíam, na época da coleta de dados, mais de 18 meses de exercício no cargo. Do universo de 40 sujeitos, foram entrevistados 30 gerentes, sendo 16 chefes de departamento e 14 coordenadores. A técnica de amostragem utilizada foi do tipo nãoprobabilístico (VERGARA, 2000), os 25\% que não foram entrevistados foi em decorrência da falta de disponibilidade dos mesmos. As estratégias de coleta de dados utilizadas foram a pesquisa documental no regimento e no estatuto da universidade pesquisada, nos regimentos dos departamentos, em documentos históricos da universidade; e a realização das entrevistas semi-estruturadas ${ }^{(4)}$.

As entrevistas foram tabuladas e analisadas, utilizando-se a análise qualitativa analítica (MELO, 1991). Nesse sentido, foi feita, primeiramente, uma análise quantitativa, em que foram identificados os principais componentes das respostas dos gerentes em cada uma das perguntas do roteiro de entrevistas, permitindo o agrupamento dos dados. Num segundo momento, foi realizada uma análise qualitativa, mediante a definição de temas emergentes e agrupamento dos estratos mais significativos das entrevistas, dando destaque à dimensão da fala do entrevistado.

\section{O Estudo de Caso}

Constatou-se uma variedade e uma complexidade de tarefas realizadas pelo gerente universitário, refletindo uma das características da função gerencial. Além das clássicas funções administrativas de Fayol (1970) tem-se, por exemplo, a gestão acadêmica $(70,00 \%)$. As atividades específicas aos gerentes de universidades são as mais ressaltadas pelos entrevistados, devido à falta de preparação formal para gerenciar e pela sua própria formação acadêmica.

As decisões ligadas aos cursos de graduação do departamento. A parte de ensino, tudo passa aqui, principalmente a de pós-graduação, pois a de graduação passa pelos centros. Tudo passa aqui e se distribui para as comissões (Entrevistado 6). 
Existem claras diferenças entre as atividades prescritas no regimento da universidade pesquisada e as atividades que são realmente realizadas pelos gerentes intermediários da instituição. O real vai muito além do prescrito e acaba por aumentar ainda mais a complexidade da função gerencial, o que reforça a constatação de Motta (1991) de não existir uma definição exata das atribuições gerenciais.

Outra atividade presente no cotidiano dos gerentes consiste em participar e coordenar reuniões (63,33\%). Enquanto eram apenas docentes, os gerentes acadêmicos também participavam de muitas reuniões, uma vez que a administração da universidade é colegiada. Contudo, ao se transformarem em chefes, eles têm incluídas em sua rotina reuniões próprias da função gerencial. Mas esta é uma das atividades que o gerente menos gosta de fazer Seus motivos são variados, indo desde a sua falta de objetividade até motivos políticos.

Você vai para a reunião e está tudo decido. Normalmente as decisões são assim. Quando você chega para a reunião está tudo decidido (Entrevistado 8).

Eu não gosto das reuniões de colegiado, pois as pessoas não entendem que aquele é um fórum de reunião de rumos do departamento, e não de embates pessoais (Entrevistado 12).

O mais difícil é participar das reuniões do conselho. Tem muita gente que parece que vai lá para descansar. Aí ficamos lá toda a vida para resolver assuntos que seriam rápidos. Eu acho que reunião tem que ser objetiva, com horário de começar e terminar. As pessoas ficam voltando para o mesmo assunto. Já até passou a votação, e eles voltam no assunto (Entrevistado 17).

A partir dos depoimentos, percebe-se a existência de um jogo de poder nas reuniões. Na análise desse fato, adota-se a concepção de Crozier (1983) de poder, em que a relação de poder nas organizações é entendida como um conjunto de relações entre os diversos atores organizacionais, mediante as quais são instituídas regras do jogo em função da possibilidade de controle das fontes de incertezas ou de recursos. Apesar de se sujeitarem às regras impostas pela universidade, as estratégias dos gerentes universitários ainda têm espaço próprio, capaz de modificar essa estrutura, por meio de suas fontes de influência e de sua habilidade em controlar as fontes de incertezas. O poder, nesse caso, assume a face de explicitar as alianças políticas em que os conchavos são estabelecidos a priori, e a reunião é utilizada apenas como palco de legitimação das decisões. As reuniões também podem servir de arena para embates pessoais entre os membros do colegiado, onde se tem um jogo em que, muitas vezes, os interesses pessoais são colocados em primeiro plano, em detrimento dos interesses institucionais e, por último as reuniões, também como estratégia para se obter um tempo para 
descansar. Os membros prolongam as discussões e criam polêmicas com o objetivo de postergarem o retorno para suas atividades cotidianas.

A gestão é vista como uma administração burocrática por 53,33\% dos entrevistados. A questão da burocracia na universidade possui elementos facilitadores e dificultadores da função gerencial. Facilitam, na medida em que estabelecem parâmetros de ação e resguardam os chefes de departamento e coordenadores; dificultam, porque tomam muito tempo e tornam as decisões mais morosas.

A gente segue as normas da CAPES. Então a gente tenta explicar tanto para o orientador como para o orientado que não é uma coisa pessoal de pegar no pé de um ou no pé de outro. É porque há uma cobrança. Isso é tanto do CNPq quanto da CAPES. E a isso nós temos vinculado os recursos das bolsas, que não é pouco dinheiro (Entrevistado 17).

Cabe ressaltar que há a preocupação dos gerentes universitários com o controle externo das agências financiadoras e o do próprio MEC, o qual não se dá exclusivamente em função dos recursos financeiros. Quando um curso é mal avaliado, além dos recursos perdidos, a culpa pelo baixo desempenho recai sobre o professor-gerente, trazendo-lhe prejuízos profissionais e comprometendo sua imagem perante seus pares e a universidade.

De acordo com 40,00\% dos entrevistados, os gerentes universitários dedicam grande parte de seu tempo à solução de problemas, que são os mais variados e abrangem desde a esfera acadêmico-administrativa até aqueles de ordem pessoal, envolvendo docentes, discentes e funcionários. Um dos problemas encontrados pelos gerentes diz respeito a como administrar seus pares com a mesma formação e, algumas vezes, até mais experientes que eles próprios.

Eu faço desde tentar resolver problemas pessoais até técnicos, dos mais variados, dentro da esfera de estar relacionado com o ser humano. Então, desde problema pessoal até problemas de ordem técnica (Entrevistado 2).

Resolver pepinos... Resolver problemas. Interessante como ser chefe de departamento é algo muito diferente de outros cargos. Por exemplo, a gente tem poucos funcionários, e a maioria é professor que tem o mesmo titulo que eu tenho, mas tem mais tempo de casa que eu. Então, é interessante você vai dar ordem para uma pessoa que é mais velha e tem a mesma formação que você (Entrevistado 4). 
Destaca-se no último depoimento a lógica das relações de poder e da cultura dentro da universidade pública. O poder do docente-pesquisador advém do conhecimento, do seu reconhecimento pela comunidade científica e pela temporalidade. Esse respeito não advém de sua capacidade gerencial, mas sim da competência como pesquisador e professor.

Apesar se todas essas atividades, os gerentes universitários não podem deixar de executar suas atribuições de professor e pesquisador em detrimento da função gerencial. Dessa forma, em suas atividades cotidianas, os gerentes acabam encontrando meios de se adaptarem à nova realidade e desenvolverem estratégias próprias para conciliar as exigências dessas atividades.

Para efeito dessa análise concebe-se que não existe uma racionalidade única na estratégia do indivíduo. Para Crozier (1983) o indivíduo tem uma autonomia que lhe permite calcular, escolher, manipular vários elementos, além de inventar e se adaptar às circunstâncias em que se encontra. Da mesma forma o comportamento é sempre ativo; mesmo a passividade é, de certa forma, uma escolha (MELO, 1991).

A primeira revelação é a de que os professores, quando se transformam em gerentes, acabam aumentando o número de horas trabalhadas (50,00\%) para dar conta de todas as atividades que já faziam e mais as atividades gerenciais (Tabela 1).

\section{Tabela 1: Estratégias de Conciliação das Atividades de Docência com a Função Administrativa}

\begin{tabular}{l|c}
\hline ITENS DISCRIMINADOS & $\mathbf{\%}$ \\
\hline Aumentar o número de horas trabalhadas & 50,00 \\
Não conseguir conciliar & 20,00 \\
Diminuir as horas de pesquisa & 16,67 \\
Reduzir o número de aulas & 13,33 \\
Contar com auxílio de estudantes de pós-graduação & 10,00 \\
Fazer administração do tempo & 10,00 \\
Priorizar ensino e administração & 6,67 \\
Descentralizar através de comissões & 6,67 \\
Abrir mão de algumas atividades & 6,67 \\
Selecionar as reuniões/eventos & 3,33 \\
Permanecer efetivamente oito horas por dia na universidade & 3,33 \\
\hline
\end{tabular}

Fonte: entrevistas com os gerentes.

Nota: a soma das freqüências é superior a 100\%, por ter sido possível aos entrevistados darem mais de uma resposta.

Olha, a gente tem um contrato de 40 horas semanais; eu trabalho umas 60 mais ou menos. É o seguinte: ou você abre mão... Não tem como manter o mesmo ritmo e ser chefe (Entrevistado 4). 
Outras estratégias de conciliação são a redução das horas de pesquisa (16,67\%) e do número de aulas (13,33\%). Essas são válidas para aqueles que estão dispostos a abrir mão de algumas atividades e que contam com a ajuda de outros docentes e/ou dos estudantes de pós-graduação (10,00\%).

Eu tenho feito o seguinte: na graduação eu tenho outro colega de área com quem divido as disciplinas, intercalando os semestres. Dá para levar uma carga horária relativa. Na pesquisa, eu tenho uma equipe; a gente trabalha com os alunos da pós. Para você ter uma idéia, atualmente eu estou orientando 5 alunos de doutorado, e eles trabalham com o plano de estudo e me auxiliam na parte de pesquisa. E tenho uma equipe de uns 10 bolsistas de iniciação cientifica que são orientados pelos alunos da pós. Então, dá para ter uma produção muito boa (Entrevistado 17).

Ainda assim, existe uma parte dos gerentes (20,00\%) que não consegue conciliar todas as atividades, o que acaba incorrendo em prejuízos profissionais, como: não conseguir novas publicações, deixar a pesquisa de lado, perder a qualidade de ensino. Essa sobrecarga de atividades é estafante e custosa para alguns entrevistados, e muitas vezes é encarada com dificuldade e implica sacrificar os finais de semana e o tempo com a família.

Eu não consigo fazer tudo e não estou me dedicando à pesquisa como gostaria. O que eu tenho deixado de lado é a pesquisa. Eu continuo orientando estudantes de mestrado, mas eu tenho deixado um pouco de lado. As minhas publicações... Eu tenho que arranjar tempo para publicar. Eu não tenho tempo assim... Eu levo trabalho para ser feito em casa. É raro eu ter um fim de semana livre. É estafante. É sobrecarga mesmo (Entrevistado 15).

A sobrecarga de trabalho, a dificuldade de planejamento e de controle das atividades são fontes de conflito e pressão para 23,33\% dos gerentes entrevistados. Essa sensação de apagar incêndios, de trabalhar muito e de não ver o resultado do trabalho e de trabalhar muitas horas além da jornada diária e semanal também são uma realidade do trabalho gerencial (MOTTA, 1991).

As principais tensões são cumprir prazos que são apertados. E a gente tem que resolver alguns casos muito rapidamente. Não é que são colocados em cima da hora. É que eu tenho tanta coisa para fazer que eu acabo tendo que fazer primeiro aquilo que é mais urgente. A gente tem que se virar com a falta de tempo (Entrevistado 15).

Outros conflitos vivenciados pelos gerentes universitários são inerentes à gestão de pessoas (23,33\%), tarefa que inclui motivar professores e funcionários (6,67\%); administrar a insatisfação dos subordinados (6,67\%); congregar professores (6,67\%); administrar conflitos interpessoais (6,67\%); lidar com mão-de-obra não qualificada (3,33\%); ser cobrado pelas pessoas (3,33\%); ser constantemente julgado 
(3,33\%); e incompreendido por pares e discentes (3,33\%). Por esse mesmo motivo, eles sentem a necessidade de desenvolver sua habilidade interpessoal, o que nem sempre é proporcionado, em razão de sua formação de professor e pesquisador.

A principal tensão que me causa realmente é administrar as relações humanas dentro da administração pública. Os cargos que tive foram na mesma situação, e eu também senti o mesmo problema. O que me causa mais tensão e mais angustia é administrar os conflitos humanos dentro do grupo. Eu sinto que eu não tenho essa habilidade. Principalmente quando se depara com radicalismos, com interesses pessoais. Eu me sinto impotente de agir dentro dessas situações (Entrevistado 27).

A manutenção da qualidade do curso/programa é considerada como um desafio para 23,33\% dos entrevistados. No atual contexto universitário, as exigências apresentadas para os gerentes, principalmente chefes de departamento e coordenadores, são: manter o bom conceito dos programas; inserir o departamento na pós-graduação $(10,00 \%)$; manter o departamento funcionando na crise (6,67\%); e melhorar curso/departamento (6,67\%). Cabe reforçar que a imagem positiva ou negativa que o curso/programa ou departamento assumir durante a gestão de determinado gerente recai, em grande parte, sobre a figura individual do professor/pesquisador.

O desafio é você manter um programa em bom nível de produção intelectual, que os seus alunos não excedam os 24 meses. A gente é avaliada em função de indicadores que pontuam seus cursos depois: manter bolsas, renovar bolsas. As agências estão cada vez mais reduzindo bolsas. Eles querem que o curso tenha um nível de excelência, mas deixam você se virar (Entrevistado 13).

Quando os conflitos dos gerentes são derivados de relacionamentos interpessoais, sua postura é a de transigência e a de evitar conflitos. Essa estratégia da transigência e da contemporização (JUNQUILHO, 2000) aparece em expressões tais como: conversar, mediar, tentar separar os problemas, não tem como reagir, ficar triste e frustrado. Pode-se perceber a transigência como um mecanismo de defesa do próprio gerente universitário e uma estratégia da própria universidade de ocultação dos conflitos, utilizada pelo gerente como representante legal da organização.

Quando convidados a falar sobre as estratégias que utilizavam no exercício da autoridade (Tabela 2), 63,33\% dos entrevistados responderam que preferem conversar com os subordinados quando ocorre algum problema. A estratégia de conversar, de adotar uma postura mais democrática, vem reforçar a prática gerencial de evitar conflitos. Esse cuidado dos gerentes decorre da administração dos pares, que foram e ainda poderão ser seus chefes. Então, existe uma tentativa de não se causar nenhum problema de enfrentamento. 


\section{Tabela 2: Estratégias Utilizadas pelos Gerentes no Exercício da Autoridade}

\begin{tabular}{lc}
\hline ITENS DISCRIMINADOS & \% \\
\hline Conversando & 63,33 \\
Aplicando as normas & 30,00 \\
Delegando para a comissão/colegiado & 13,33 \\
Utilizando o poder do cargo/com firmeza & 6,67 \\
Brigando/ ficando nervoso & 6,67 \\
Utilizando a ética & 3,33 \\
Não tem autoridade & 3,33 \\
\hline
\end{tabular}

Fonte: entrevistas com os gerentes.

Nota: a soma das freqüências é superior a 100\%, por ter sido possível aos entrevistados darem mais de uma resposta.

Primeiro eu procuro conversar. Tem que ir com cuidado. Primeiro porque você... Eu entendo que eu não sou chefe. Eu estou chefe por um tempo, porque depois eu vou voltar à minha atividade como professor e outro colega vai assumir aqui. Então, a gente não vai... Isso aqui é temporário. Então, você tem que dialogar muito para não criar nenhum problema dentro do departamento (Entrevistado 3).

Normalmente, quando, por meio da conversa, o gerente universitário não consegue atingir o seu objetivo, ele utiliza a aplicação das normas e do regimento (30,00\%) ou joga a decisão para a comissão ou colegiado (13,33\%). Tanto a aplicação das normas quanto a decisão do colegiado tiram o caráter pessoal da decisão do gerente e ajudam a protegê-lo de sanções dos pares em função da alternância no cargo.

Quando é um caso complicado, eu coloco nas mãos do colegiado. O colegiado decide se vai punir a pessoa ou não. Dessa forma não é a autoridade do chefe de departamento fulano de tal que está em jogo e sim a autoridade do colegiado (Entrevistado 23).

\section{Contexto Social e a Dinâmica da Universidade}

A universidade pesquisada, na perspectiva dos docentes com cargos de chefia intermediária (Tabela 3) é caracterizada por um efetivo compromisso dos docentes (46,67\%) com a instituição, porquanto, localizada no interior do Estado, não oferece outras oportunidades de trabalho como nos grandes centros; tradição agrária (23,33\%); conflito entre o novo e o antigo (20,00\%), resistência a mudanças $(13,33 \%)$, entre outras. 


\section{Tabela 3: Fatores que Caracterizam a Cultura da UFV, na Opinião dos Entrevistados}

\begin{tabular}{lc}
\hline ITENS DISCRIMINADOS & \% \\
\hline Compromisso do corpo docente & 46,67 \\
Valorização das ciências da natureza/hegemonia das ciências agrárias & 23,33 \\
Localização no interior & 16,67 \\
Resistência a mudanças & 13,33 \\
Ambigüidade cultural/dilema entre a tradição e a renovação & 13,33 \\
Senso de honestidade & 6,67 \\
O amor das pessoas pela universidade & 6,67 \\
Os estudantes moram na UFV & 6,67 \\
A cidade depende economicamente da UFV & 6,67 \\
Supervalorização do professor/corporativismo & 6,67 \\
Maior aproximação estudantes e professores & 6,67 \\
Filosofia de orçamento compartilhado & 3,33 \\
Concorrência entre os departamentos & 3,33 \\
Orientação para resultados & 3,33 \\
Cobrança por metas & 3,33 \\
Sentido de universidade & 3,33 \\
Qualidade de trabalho & 3,33 \\
Sensibilidade para os problemas pessoais dos estudantes & 3,33 \\
Nenhum é a cultura da universidade pública. & 16,67 \\
\hline
\end{tabular}

Fonte: entrevistas com os gerentes.

Nota: a soma das frequiências é superior a 100\% por ter sido possível aos entrevistados darem mais de uma resposta.

A tradição agrária da universidade está ligada à sua formação histórica, cujo objetivo inicial consistia em profissionalizar a agricultura mineira. Atualmente a universidade é dividida em quatro centros de ciências; dois vinculados às ciências da natureza e dois a outras áreas do conhecimento. Contudo, existe uma verdadeira guerra entre esses centros pelo poder. Os membros dos primeiros argumentam que os outros não desenvolvem pesquisas e não incorporaram os valores tradicionais da universidade.

Nós das Ciências Agrárias temos o orgulho de ser os melhores. Eu não sinto muito isso nos departamentos mais novos. Há cursos, por exemplo, que não têm nada de pesquisa. Eles não têm aquele orgulho. Eles não são como o pessoal de Ciências Agrárias (Entrevistado 17).

Por outro lado, os outros centros, considerados mais pobres, lutam por mais atenção, por uma distribuição mais igualitária de recursos, ou seja, por um lugar ao sol. A situação acaba transformando-se num círculo vicioso, onde o grupo dos poderosos e influentes sempre logra mais recursos e exercendo mais poder. 
Hoje, esses aspectos (culturais) estão extremamente relacionados com os grupos de poderosos e influentes, tendo recursos físicos e humanos maiores que o restante. Basicamente, o desafio gerencial se refere ao relacionamento de grupos incipientes com o de grupos poderosos (Entrevistado 1).

A universidade pesquisada passa por um processo de transformação cultural muito grande, com reflexo nas práticas gerenciais. E esse processo decorre da transição de uma autocracia (como era administrada desde sua fundação) para uma democracia (tendência da administração da última década), além das mudanças no ensino superior como um todo e da convivência de cursos que não são da área agrária. Esses cursos novos normalmente são formados por docentes de outras instituições de ensino superior, que vêm com nova carga cultural. Valores novos e valores conservadores entram em choque, fazendo emergir uma série de conflitos, que demandam gerenciamento adequado de forma a não prejudicar o desempenho da universidade e, até mesmo, de potenciar as mudanças necessárias ao seu bom desempenho em novo cenário. Como não houve nenhuma preparação para esse processo de transformação, ela acaba acontecendo de forma caótica, gerando medo e resistência nos membros da instituição.

Infelizmente, muitos valores se perderam, pois as mudanças foram muito grandes e drásticas. Então, aquela cultura antiga de que o mais importante é a mãe, que é a universidade, em muitos casos parece que está se perdendo. Hoje, às vezes, se preocupam mais com o eu, com o seu interesse, do que com o comunitário, do que com o grupo e a instituição quer. E isso acentua as diferenças e começa a criar uma serie de conflitos. E, às vezes, em vez de sermos parceiros nos tornamos concorrentes (Entrevistado 7).

Entre os aspectos culturais da universidade, destaca-se também a influência da cultura local da cidade. A sociedade local, segundo Paniago (1990), está vinculada a valores tradicionais, principalmente no que tange à política e à religião. A autora ressalta que numa cidade de base agrária, em que a maioria das famílias vive ligada à universidade, os valores políticos vinculados ao coronelismo e ao familismo estão fortemente presentes.

Esses valores políticos são encontrados na própria universidade. Tem-se o tradicionalismo como marca presente para 36,67\% dos gerentes universitários entrevistados. Outros aspectos típicos da cultura nacional e das cidades do interior mineiro também se encontram presentes como o personalismo (13,33\%), misturar a vida pessoal com a profissional (10,00\%) e o familismo (10,00\%). Por exemplo, têm-se várias pessoas de uma mesma família trabalhando na universidade, onde todo o mundo conhece todo o mundo. O familismo inicia-se quando uma pessoa começa a trabalhar na universidade e acaba trazendo seus familiares. 
Eu acho que, como todo interior, onde as pessoas trabalham muito na informalidade. As pessoas têm muita facilidade. Todo mundo conhece todo mundo. E acha que na universidade vai ser a mesma coisa. Se tem alguém que conheço no setor tal eu me dirijo a ele, pois ele vai me ajudar a desenvolver mais rápido aquilo que eu estou me propondo fazer (Entrevistado 12).

No caso da alta administração da universidade, os gerentes entrevistados argumentam que os reitores normalmente atendem a grupos preestabelecidos antes das eleições (26,67\%). Normalmente, essa prática se reflete na distribuição de cargos de confiança (16,67\%) e no privilégio de algumas alas da universidade em que o reitor tem maior força eleitoral. Dessa forma, ele acaba preparando seus possíveis sucessores com o intuito de manter o poder dentro do mesmo grupo. Nesse caso, predomina a individualidade sobre a coletividade e o aspecto político sobre o gerencial.

No caso da administração superior, formam grupos, criam-se compromissos e acabam entrando pessoas que não são competentes para assumirem o cargo (Entrevistado 17).

As relações paternalistas também são percebidas no âmbito da reitoria. No caso da universidade, os reitores assumem posturas paternalistas para manteremse no poder e podem fazer uso de retaliações, como diminuição de recursos para aquele setor que lhe faz oposição.

É o paternalismo. Isso dificulta muito, porque, às vezes, você tem de tomar certa decisão e não toma porque existe um paternalismo muito grande. E o reitor, de modo geral, sempre procura não exercer com muito rigor, quando necessário, uma determinada ação contra um funcionário, contra um professor. Se o reitor quiser ser reeleito, ele não pode tomar muita decisão antipática (Entrevistado 25).

Quando perguntados sobre suas próprias práticas gerenciais à frente da chefia do departamento ou da coordenação do curso/programa, os entrevistados saem pela tangente e não reconhecem a influência da cultura em sua ação. Eles argumentam que cada um tem sua forma própria de agir e que os aspectos culturais, como tradicionalismo, tradição agrária, personalismo, resistência a mudanças e familismo, não influenciam em nada a sua atuação. Essa pode ser vista como estratégia de autoproteção. Os entrevistados têm consciência do processo cultural e de que suas práticas gerenciais produzem e reproduzem a cultura. Contudo tendem a dar uma resposta, que eles consideram politicamente correta, de que eles próprios são imunes a esse processo.

O que eu vejo são grupos, comportamentos e atitudes que são claramente distintos e refletem a estrutura de poder dentro da universidade. Os chefes dos departamentos tradicionais têm uma atitude muito clara de manter e reforçar o statu quo. Na verdade, crescer mais ainda. Falta, para mim, uma visão de conjunto, de pensar na universidade (Entrevistado 5). 
O aspecto político da universidade assume seu caráter mais presente, quando se analisa a questão das alianças (Tabela 4) entre grupos e pessoas na universidade que são formadas privilegiando o aspecto político (46,67\%), ou o lado das amizades e afinidades pessoais (33,33\%), ou a questão profissional de temas de pesquisa (23,33\%), ou as afinidades das áreas de conhecimento (6,67\%).

Tabela 4: Fontes das Alianças na Universidade Pesquisada

\begin{tabular}{lc}
\hline ITENS DISCRIMINADOS & $\mathbf{\%}$ \\
\hline Questões políticas para tomar o poder & 46,67 \\
Amizades/afinidades pessoais & 33,33 \\
Temas de pesquisa & 23,33 \\
Afinidades das áreas. & 6,67 \\
Em torno das pessoas que se destacam & 6,67 \\
Tendência natural da evolução humana & 3,33 \\
Objetivos em comum & 3,33 \\
Em torno das pessoas que detêm maiores informações & 3,33 \\
Aqueles que detêm maiores recursos & 3,33 \\
Interesses pessoais & 3,33 \\
Em torno de correntes partidárias & 3,33 \\
Não vê nenhuma forma de aliança & 3,33 \\
\hline
\end{tabular}

Fonte: entrevistas com os gerentes.

Nota: a soma das freqüências é superior a $100 \%$, por ter sido possível aos entrevistados darem mais de uma resposta.

Em se tratando especificamente das alianças políticas, os entrevistados reconhecem o forte vínculo político da universidade e a existência de departamentos mais fortes e mais articulados politicamente. Os grupos políticos e a disputa pelo poder ficam mais evidenciados em época de eleição para reitor.

Isso tem demais. Não sei se é só aqui. Mas existem os grupos voltados para determinado objetivo. Você percebe isso principalmente na época de eleiçãodentro da universidade. Os grupos começam a aparecer, formando suas chapas, estabelecendo as alianças (Entrevistado 3).

No sentido profissional ou acadêmico, as alianças são formadas também em torno de temas de pesquisa e áreas de interesse. Contudo esse tipo de aliança não exclui a questão política. E o núcleo de pesquisa pode ser até o início da formação de grupos políticos, baseados em interesses e ambições pessoais pela busca do poder. O movimento de formação de alianças é contínuo e tem seu ápice por ocasião da eleição do reitor e da distribuição de cargos após a sua posse. 
Sob o aspecto técnico-profissional, sob pesquisa e extensão, são feitas das afinidades pessoais, interesses técnicos. Agora administrativamente, infelizmente, agente sente que essas alianças são mais movidas pelos interesses pessoais do que institucionais, por ambições pessoais (Entrevistado 27).

Apesar de reconhecerem a existência das alianças políticas e de enfatizarem esse aspecto até como fazendo parte da tradição da universidade, os entrevistados assumem o discurso da imparcialidade (36,67\%), quando convidados a falar de suas estratégias para lidar com essas alianças. Os gerentes universitários se colocam como se não participassem do processo. Contudo, se não participassem do processo político, não teriam sido indicados para o cargo de chefe de departamento ou de coordenadores de curso/programa. Novamente, os entrevistados tentam proteger-se, pois política é vista como valor negativo na sociedade brasileira. A negação do conflito ou de alguma estratégia para formar alianças políticas consiste, por si só, em mecanismo para mediar a existência dos conflitos.

Eu nunca participei disso, mesmo no passado. Eu não sou muito chegado a essas coisas. Eu acho que sempre que se formam grupos você gera certo protecionismo daqueles que não têm capacidade para assumir cargos e acabam assumindo. Então eu não participo disso (Entrevistado 17).

Essa visão do poder como algo negativo, prejudicial, é contestada por Crozier (1983), pois as alianças, os jogos de poder existem, são inevitáveis e essenciais para a existência das organizações, principalmente em se tratando de uma universidade.

\section{Considerações Finais}

A análise dos relatos dos entrevistados demonstrou que as funções dos chefes de departamento e coordenadores da universidade pesquisada extrapolam as relativas ao processo administrativo, ou seja, o planejamento, a organização, o comando, a coordenação e o controle. Suas funções estão diluídas e incorporadas em práticas sociais, colaborando com estudos sobre trabalho gerencial, que enfocam que as atividades do gerente são executadas sem planejamento, imperando o imediatismo, a sensação de apagar incêndios e o improviso.

Entretanto, às atividades dos gerentes universitários somam-se as atividades de docente e de pesquisador, o que acarreta sobrecarga de trabalho. Nesse caso, eles utilizam como recurso aumentar o número de horas trabalhadas, 
levar trabalho para casa, diminuir as atividades de pesquisa e de docência e, contar com o auxílio dos estudantes de pós-graduação, normalmente seus orientandos nas atividades de pesquisa e ensino, para conciliar todas as atividades.

A postura de se evitar conflitos e tentar conversar e negociar é utilizada pelo gerente universitário no que se refere ao uso de sua autoridade. De maneira geral, a política de não enfrentamento é um recurso para a sua manutenção no cargo.

O gerente universitário tem na gestão de pessoas sua principal fonte de conflitos e pressões. Administrar grupos, principalmente seus pares docentes, com interesses divergentes, e fazer com que eles trabalhem em equipe é, além de fonte de conflito, um desafio gerencial.

A universidade pesquisada vive um período de ambigüidade cultural (dilema entre a tradição e a renovação), uma concorrência entre seus departamentos por recursos e poder de influência, a presença de verdadeiros feudos por área de conhecimento, uma burocracia profissional associada ao personalismo, uma descontinuidade estratégica, um favorecimento político de alguns grupos e indivíduos, e o predomínio da individualidade sobre a coletividade.

As alianças entre grupos e pessoas na universidade são formadas privilegiando-se o aspecto político e o das amizades e afinidades pessoais, o que remete à questão do familismo e do personalismo. Os gerentes intermediários fazem parte de grupos políticos, apesar de não o assumirem verbalmente.

Este estudo contribuiu para o conceito de gestão como prática social, em que o gerente, além de ser influenciado pelas políticas da organização, também é capaz de influenciá-las. Diante disso, o reconhecimento das diferenças culturais entre as organizações e a compreensão da cultura e da realidade da universidade tornam-se cruciais ao sucesso das práticas gerenciais.

\section{Artigo recebido em 16.09.2003. Aprovado em 08.12.2004.}

\section{Notas}

\footnotetext{
${ }^{1}$ Entende-se por prática social “a participação num conjunto de ações, inteligíveis à luz dos pressupostos que as informam, orientadas para fins partilhados por todos os membros da comunidade envolvida em tais ações, e definindo-se pelos meios adotados para a realização
} 
desses fins, os quais são determinados pelas condições em que as mesmas se efetuam” (HARRIS, 1980 apud REED, 1997).

${ }^{2}$ Fleury (1990, p. 22) define cultura organizacional como: “um conjunto de valores e pressupostos básicos expressos em elementos simbólicos, que em sua capacidade de ordenar, atribuir significações, construir a identidade organizacional, tanto agem como elemento de comunicação e consenso, como ocultam e instrumentalizam as relações de dominação”.

${ }^{3}$ DILL, D. The management of academic culture: notes on the integration on the management of meaning and social integration, Higher education, 11, p. 303-320, 1992.

${ }^{4}$ As entrevistas semi-estruturadas (VERGARA, 2000) seguiram um roteiro prévio, mas permitiram algumas interferências da pesquisadora, quando necessário.

\section{REFERÊNCIAS BibLIOGRÁFICAS}

BARBOSA, L. N. H.

Cultura administrativa: uma nova perspectiva das relações entre antropologia e administração. Revista de Administração de Empresas. São Paulo, v. 36. n. 4, p. 6-19, out./nov. 1996.

BARNARD, C.

As Funções do Executivo. 2. ed. São Paulo: Atlas, 1971. p. 322.

BARROS, B. T.;

PRATES, M. C.

O estilo brasileiro de administrar. 1 . ed. São Paulo: Atlas, 1996. p. 148.

CAVEDON, N. R.;

FACHIN, R. C.

Homogeneidade versus heterogeneidade cultural: um estudo em universidade pública. In: ENCONTRO ANUAL DA ANPAD, 24, 2000, Rio de Janeiro. Anais... Rio de Janeiro: ANPAD, 2000. p. 15-31.
CROZIER, M.

A sociedade bloqueada. 2. ed. Brasília: Editora UnB, 1983. p. 198.

DAGNINO, R.;

GOMES, E. O

Processo Decisório na Universidade Pública Brasileira: uma visão de análise de política. In: Sala de Leitura da CTS+I, 2001. Disponível em: <http://www.oei.es>. Acesso em: 20 fev. 2003.

DILL, D.

The management of academic culture: notes on the integration on the management of meaning and social integration, Higher education, London, v. 11, n. 3, p. 303-320, july/ sept. 1992. 
FAYOL, H.

Administração industrial e geral. 8. ed. São Paulo: Atlas, 1970. p. 149.

FREITAS, A. B.

Traços brasileiros para uma análise organizacional. In: MOTTA, F. C. P.; CALDAS, M. P. (Orgs.). Cultura organizacional e cultura brasileira. 1. ed. São Paulo: Atlas, 1997. p. 325.

HERGUNER, G.;

REEVES, N. B. R.

Going against the national cultural grain: a longitudinal case study of organizational culture in Turkish higher education. In: Total quality Management, 1. ed. London: SAGE Abingdon, jan. 2000. p. 17-25.

JUNQUILHO, G. S.

Ação gerencial na administração pública: a reprodução de "raízes" brasileiras, 2000. 310 f. Tese (Doutorado em Administração) Faculdade de Ciências Econômicas, Universidade Federal de Minas Gerais, Belo Horizonte.

LIKERT, R.

Novos padrões de administração. 2 ed. São Paulo: Pioneira, 1979. p. 307.

MARTIN, J.

Cultures in Organizations: three perspectives. 1. ed. Oxford: Oxford University press, 1992. p. 228.

MATTA, R. da

Carnavais, malandros e heróis: para uma sociologia do dilema brasileiro. 5 . ed. Rio de Janeiro: Guanabara, 1990. p. 350.
A casa e a rua: espaço, cidadania, mulher e morte no Brasil. 5. ed. Rio de Janeiro: Rocco, 1997. p. 177.

MELO, M. C. O. L. O.

Estratégias do trabalhador informático nas relações de trabalho, 1991. $380 \mathrm{f}$. Tese (Professor titular) - Faculdade de Ciências Econômicas, Universidade Federal de Minas Gerais, Belo Horizonte.

MINTZBERG, H.

Trabalho do executivo: o folclore e o fato. Coleção Harvard de Administração. 1. ed. São Paulo: Abril S. A. 1973. p. 102.

MOTTA, P. R.

Gestão contemporânea: a ciência e a arte de ser dirigente. 2. ed. Rio de janeiro: Record, 1991. p. 256.

PANIAGO, M. C. T.

Viçosa - mudanças socioculturais: evolução histórica e tendências. 1. ed. Viçosa: UFV, Imprensa Universitária, 1990. p. 270.

REED, $M$.

Sociologia da gestão. 1. ed. Lisboa: Celts, 1997. p. 147.

RODRIGUES, S. B.

$O$ chefinho, o telefone e o bode: autoritarismo e mudança cultural no setor de telecomunicações, 1991. 317 f. Tese (Professor titular) - Faculdade de Ciências Econômicas, Universidade Federal de Minas Gerais, Belo Horizonte. 
VERGARA, S. C.

Projetos e relatórios de pesquisa em administração. 3. ed. São Paulo, Atlas, 2000. p. 92.

\section{WEBER, M.}

Ensaios de sociologia. 5. ed. Rio de Janeiro: Ed. Guanabara, 1982. p. 530. 